\title{
THE ASSESSMENT OF FELLOWS COMPETENCES BASED ON RHEUMATOLOGY ENTRUSTABLE PROFESSIONAL ACTIVITIES IS FEASIBLE AND INFORMATIVE
}

\author{
Rafael Mendonça da Silva Chakr ${ }^{1, \star}$ \\ 1.Universidade Federal do Rio Grande do Sul, Porto Alegre (RS), Brazil. \\ ${ }^{\star}$ Corresponding author: rchakr@hcpa.edu.br
}

\section{BACKGROUND}

During rheumatology training, assessment of competences is vital to guide learning and to guarantee quality of care1. Rheumatology entrustable professional activities (EPAs) are the comprehensive set of tasks or responsibilities that any practicing rheumatologist should be capable of performing2. Our goal is to report an EPA-based assessment of competences during fellowship training.

\section{METHODS}

In June 2021, all trainers from a university hospital were invited to anonymously fulfill a questionnaire with the 14 rheumatology EPAs according to the American College of Rheumatology2 and the names of the first year (F1) and second year (F2) fellows underneath every EPA. For each EPA, trainers should mark which fellows were totally capable of performing it independently (fully competent). As part of the training, fellows participate in daily theoretical and practical activities with hospitalized and ambulatory patients of any age. The average time spent in fellowship activities is $60 \mathrm{~h} /$ week with permanent supervision provided by at least one experienced rheumatologist according to the national regulatory educational competency matrix.

\section{RESULTS}

Nine trainers responded to the questionnaire on six trainees (three F1 and three F2). By the time the assessment was performed, F1 had completed four months of training, and F2 had completed 16 months, half of which with severe practical activities contingency due to the COVID-19 pandemic. Figure 1 depicts the average percentage of trainers that considered F1 and F2 fully competent for each rheumatology EPA. Based on the pool of anonymous trainers' perceptions, individualized feedback could be provided

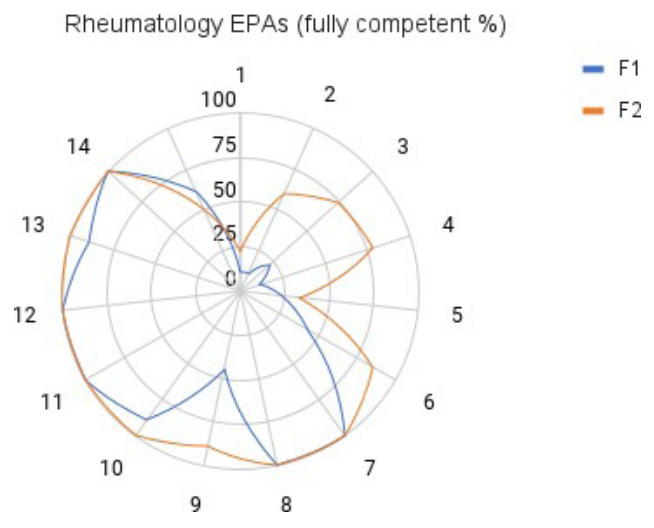

Note. 1. Manage the care of patients with acute and chronic, common and complex rheumatologic diseases across multiple care settings; 2 . Demonstrate expertise in the performance and interpretation of the musculoskeletal examination; 3. Demonstrate expertise in the indications for and interpretation of diagnostic tests and imaging studies relevant to the evaluation of patients with suspected or established rheumatic and musculoskeletal diseases; 4 . Prescribe and manage immunomodulatory therapy; 5. Perform procedures including arthrocentesis and injections, compensated polarized microscopy, and interpretation of synovial fluid analysis; 6 . Provide rheumatology consultation to other specialties and providers; 7. Demonstrate professional, compassionate, and ethical behavior; 8 . Effectively communicate and manage transitions of care with other health care providers; 9 . Collaborate and work effectively as a member or leader of interprofessional health care teams; 10 . Facilitate the learning of patients, families, and members of the interprofessional team; 11. Enhance and promote patient safety and the quality of health care at both the individual and systems level; 12. Advocate for individual patients; 13. Contribute to the fiscally sound and ethical management of a practice; 14. Engage in lifelong learning.

Figure 1. Average percentage of trainers considering first year (F1) and second year (F2) fellows fully competent for each rheumatology EPA.

Realização: 
to trainees by the fellowship program director, taking into account the average percentage by peers of the same year of training. Among the overall unmet needs were the intensification of physical examination training for F2 to overcome the inactive period due to the COVID-19 pandemic, the rotation at the radiology department to improve the expertise in indications for and interpretation of imaging studies and the implementation of a compensated polarized microscopy training program, that is currently inexistent.

\section{CONCLUSION}

The assessment of competences based on rheumatology EPAs is feasible and informative, as it provides a comprehensive overview of trainees progress and allows individualized opportunities for feedback and improvement. Also, strengths, weaknesses and unmet needs of the fellowship training can be clearly identified and a set of short-term and long-term opportunities can be put into perspective in the program agenda.

\section{KEYWORDS}

EPA, Fellowship, Training.

\section{REFERENCES}

1. Sivera F, Alunno A, Najm A, Avcin T, Baraliakos X, Bijlsma JW, et al. 2019 EULAR points to consider for the assessment of competences in rheumatology specialty training. Ann Rheum Dis. 2021;80(1):65-70. https://doi.org/10.1136/annrheumdis-2020-218015

2. Brown Junior CR, Criscione-Schreiber L, O'Rourke KS, Fuchs HA, Putterman C, Tan IJ, et al. What is a rheumatologist and how do we make one? Arthritis Care Res. 2016 Aug;68(8):1166-72. https://doi.org/10.1002/acr.22817 